\title{
What Effect Does Epstein-Barr Virus Have on Extranodal Natural Killer/T-Cell Lymphoma Prognosis? A Review of 153 Reported Cases
}

\author{
Erika Tvedten ${ }^{1}$, Jordan Richardson ${ }^{1}$, Kiran Motaparthi ${ }^{2}$ \\ 1. Department of Dermatology, Michigan State University, Detroit, USA 2. Department of Dermatology, University of \\ Florida, Gainesville, USA
}

Corresponding author: Erika Tvedten, tvedten2@msu.edu

\begin{abstract}
The primary aim of this review is to identify the relationship between Epstein-Barr virus (EBV) and prognosis in extranodal natural killer/T-cell lymphoma (ENKTL). Additionally, a literature review of ENKTL was carried out. The investigators designed and implemented a 21-year literature review using the online databases PubMed and Google Scholar. The total number of cases analyzed was 153 (64 case reports; one comparative study; one systematic review). Information related to ENKTL from July 1999 to February 2021 was included in the study. Study variables included: patient demographics, tumor classification, screening modalities, tumor characteristics, symptomatology, treatment, and prognosis. The average age at diagnosis was 50.9 years (range: $4-90$ years). Patients of Asian ethnicity were most commonly affected, and there was a 1.6:1 male to female ratio. ENKTL was most frequently detected in the head and neck region, and $53.1 \%$ of cases metastasized. Of all head and neck cases, the nose was the most affected location. Immunohistochemistry positivity included: EBV (32.0\%), CD2 (96.6\%), CD3€ (81.7\%), CD43 (91.7\%), CD56 (86.4\%), Granzyme (97.1\%), Perforin (90.9\%), TIA-1 (97.8\%), p53 (33.3\%). The most frequently employed single treatment modality was chemotherapy alone, and $34.2 \%$ of patients expired within five years of diagnosis. The average follow-up period was 16.51 months (range: 0.25-66 months). EBV was significantly associated with metastatic ENKTL $\left(\chi^{2}=4.36 ; \mathrm{CV}=3.84 ; \mathrm{p}=0.037\right)$. We found no association between EBV and ENKTL prognosis $\left(\chi^{2}=17.2 ; C V=21.0 ; p=0.14\right)$.
\end{abstract}

Review began 08/05/2021 Review ended 09/09/2021 Published 09/15/2021

๑) Copyright 2021

Tvedten et al. This is an open access article distributed under the terms of the Creative Commons Attribution License CC-BY 4.0., which permits unrestricted use, distribution, and reproduction in any medium, provided the original author and source are credited.
Categories: Pathology, Oncology, Epidemiology/Public Health

Keywords: enktl, epstein-barr virus, literature review, immunohistochemical, non-hodgkin lymphoma nhl

\section{Introduction And Background}

Extranodal natural killer/T-cell lymphoma (ENKTL) is an extremely rare subtype of non-Hodgkin lymphoma $(\mathrm{NHL})$ that historically has a very low survival rate $[1]$ and is frequently associated with Epstein-Barr virus (EBV) infection. ENKTL, a non-nasal type is a distinct clinicopathologic entity from nasal NK/T-cell lymphoma [2]. This definition was revised in 2016 by the World Health Organization (WHO) where it was determined that all cases of ENKTL were to be classified under the nasal category [3]. It is currently debated whether the diagnosis of ENKTL requires the identification of EBV infection.

Classically, ENKTL is treated with chemotherapy [4]. Radiation therapy is an essential component in the treatment of ENKTL and plays an important role in improving five-year overall survival $[4,5,6]$.

The purpose of this paper is to answer the following clinical question, "In those subjects who have ENKTL, does EBV positivity incur a favorable prognosis?” Subject-oriented variables including demographics, imaging, diagnostic modalities, immunohistochemical profile, symptomatology, tumor location, treatment, and prognosis were investigated. The authors hypothesized that this study would reject the null hypothesis and reveal an association between EBV positivity and the prognosis of ENKTL. The aim of this study is to review the current literature concerning ENKTL as well as to elicit any relationships that exist between EBV and ENKTL.

\section{Review \\ Methods}

Medical subject heading (MeSH) terms used for the search was "Extranodal NK/T-cell Lymphoma." This MeSH term was used in search engines: PubMed and Google Scholar to search for articles concerning ENKTL. The Preferred Reporting Items for Systematic Reviews and Meta-Analyses (PRISMA) diagram illustrates the steps of screening and analyzing, scrutinizing the various articles during the selection process of the reports for this review (Figure 1). 


\section{Cureus}

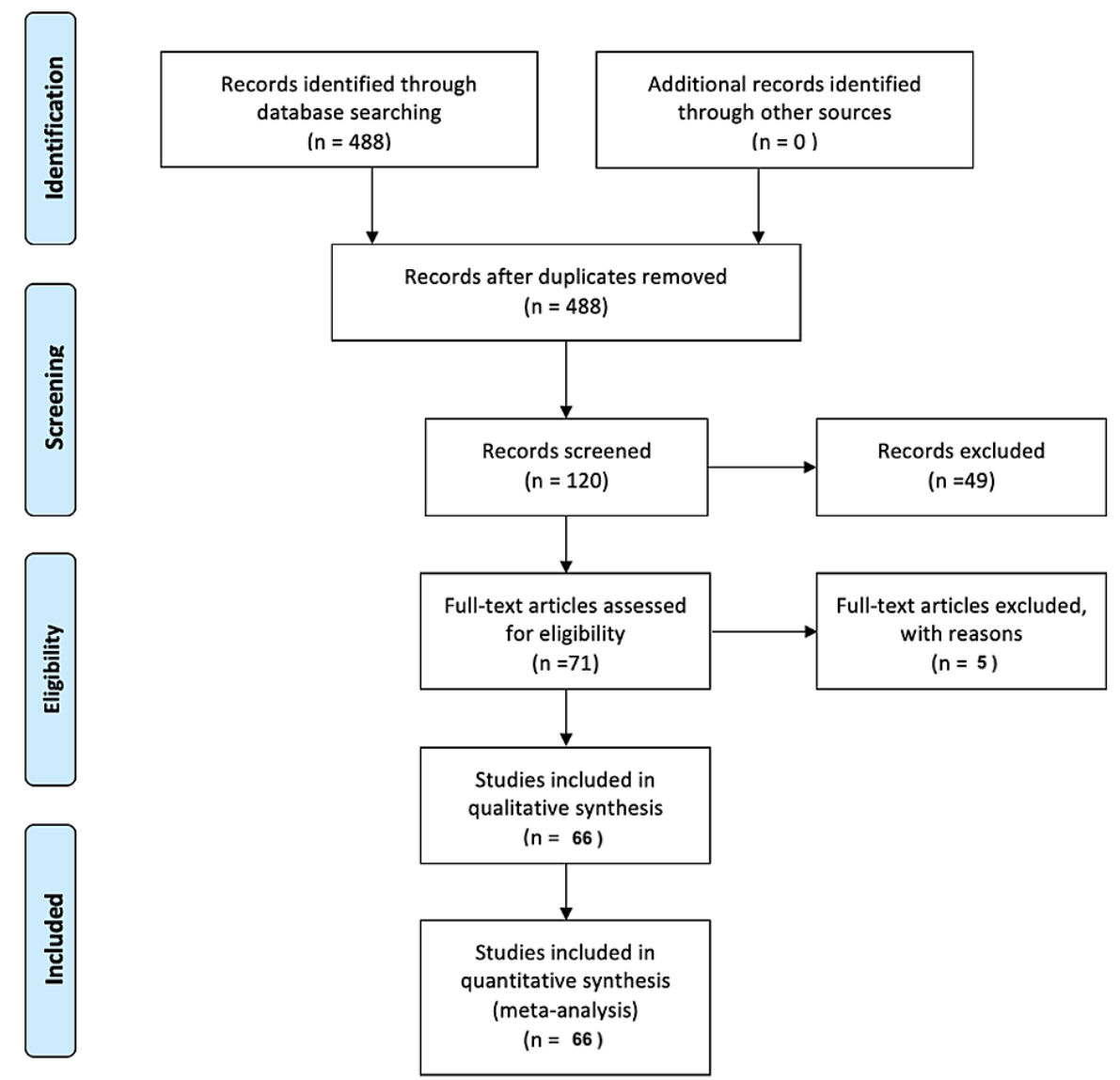

FIGURE 1: PRISM diagram.

PRISM: Preferred Reporting Items for Systematic Reviews and Meta-Analyses.

Case reports, comparative studies, and systematic reviews on ENKTLs published in the English language between July 1999 and February 2021 were included. Literature that was not in the English language, not published in a peer-reviewed journal, or an animal, cadaveric, or histopathologic study without clinical information was excluded. Articles describing a previously published case were excluded to avoid double counting. The following data was collected from each study: author name, publication year, study type, patient age and gender, nasal or non-nasal classification, imaging and diagnostic modalities utilized, immunohistochemical profile, tumor location (including extension and metastasis), symptomatology, treatment, and prognosis. Data analyses were performed using Microsoft Excel 2020 version 16.35 and statistical calculations were performed using SPSS version 26 for Mac (IBM Corp., Armonk, NY, USA). Descriptive statistics were presented as mean and range for continuous variables.

\section{Results}

On the basis of inclusion criteria, 66 articles reflecting 153 cases of ENKTL were included for final review and analysis, published over the span of the past 21 years (1999-2020) [6-77]. Overall, 18.8\% of the cases included came from a comparative study, $80.0 \%$ were from case reports and $1.2 \%$ were from systematic reviews.

The mean age was 50.9 years (range: $4-90$ years), with a ratio of male-to-female patients of 1.6:1. Patients of Asian descent (54.6\%) were most frequently affected, followed by Caucasians (9.2\%). The majority of cases were classified as the nasal type (45.8\%) compared to the less common non-nasal type (18.3\%) (Table 1). 


\section{Cureus}

\begin{tabular}{|c|c|}
\hline Unspecified & $3(2.5 \%)$ \\
\hline \multicolumn{2}{|l|}{ Ethnicity } \\
\hline Asian & $65(54.6 \%)$ \\
\hline Caucasian & $11(9.2 \%)$ \\
\hline African American & $2(1.7 \%)$ \\
\hline Hispanic & $2(1.7 \%)$ \\
\hline Other & $6(5.0 \%)$ \\
\hline Unspecified & $33(27.7 \%)$ \\
\hline \multicolumn{2}{|l|}{ Type } \\
\hline Nasal & $55(45.8 \%)$ \\
\hline Non-nasal & $22(18.3 \%)$ \\
\hline Unspecified & $43(35.8 \%)$ \\
\hline \multicolumn{2}{|l|}{ Study Type } \\
\hline Comparative Study & $15(18.8 \%)$ \\
\hline Case Report & $64(80.0 \%)$ \\
\hline Systematic Review & $1(1.2 \%)$ \\
\hline \multicolumn{2}{|l|}{ Primary Site } \\
\hline Head \& Neck & $57(47.5 \%)$ \\
\hline Gl Tract & $6(5.0 \%)$ \\
\hline Lung & $1(0.8 \%)$ \\
\hline Testes & $2(1.7 \%)$ \\
\hline Bone & $1(0.8 \%)$ \\
\hline Skin & $14(11.7 \%)$ \\
\hline Lymph Node & $3(2.5 \%)$ \\
\hline Adrenal Glands & $2(1.7 \%)$ \\
\hline Breast & $2(1.7 \%)$ \\
\hline Soft Tissue & $4(3.3 \%)$ \\
\hline Prostate Glands & $1(0.8 \%)$ \\
\hline Female Reproductive Tract & $2(1.7 \%)$ \\
\hline More than one site & $5(4.2 \%)$ \\
\hline Miscellaneous & $8(6.7 \%)$ \\
\hline Unspecified & $12(10.0 \%)$ \\
\hline \multicolumn{2}{|l|}{ Head \& Neck Sites } \\
\hline Nose & $31(54.4 \%)$ \\
\hline Nasopharynx & $2(3.5 \%)$ \\
\hline Tonsil & $5(8.8 \%)$ \\
\hline Hard Palate & $4(7.0 \%)$ \\
\hline Tongue & $1(1.8 \%)$ \\
\hline Oral Cavity & $2(3.5 \%)$ \\
\hline Paranasal Sinuses & $3(5.3 \%)$ \\
\hline
\end{tabular}




\section{Cureus}

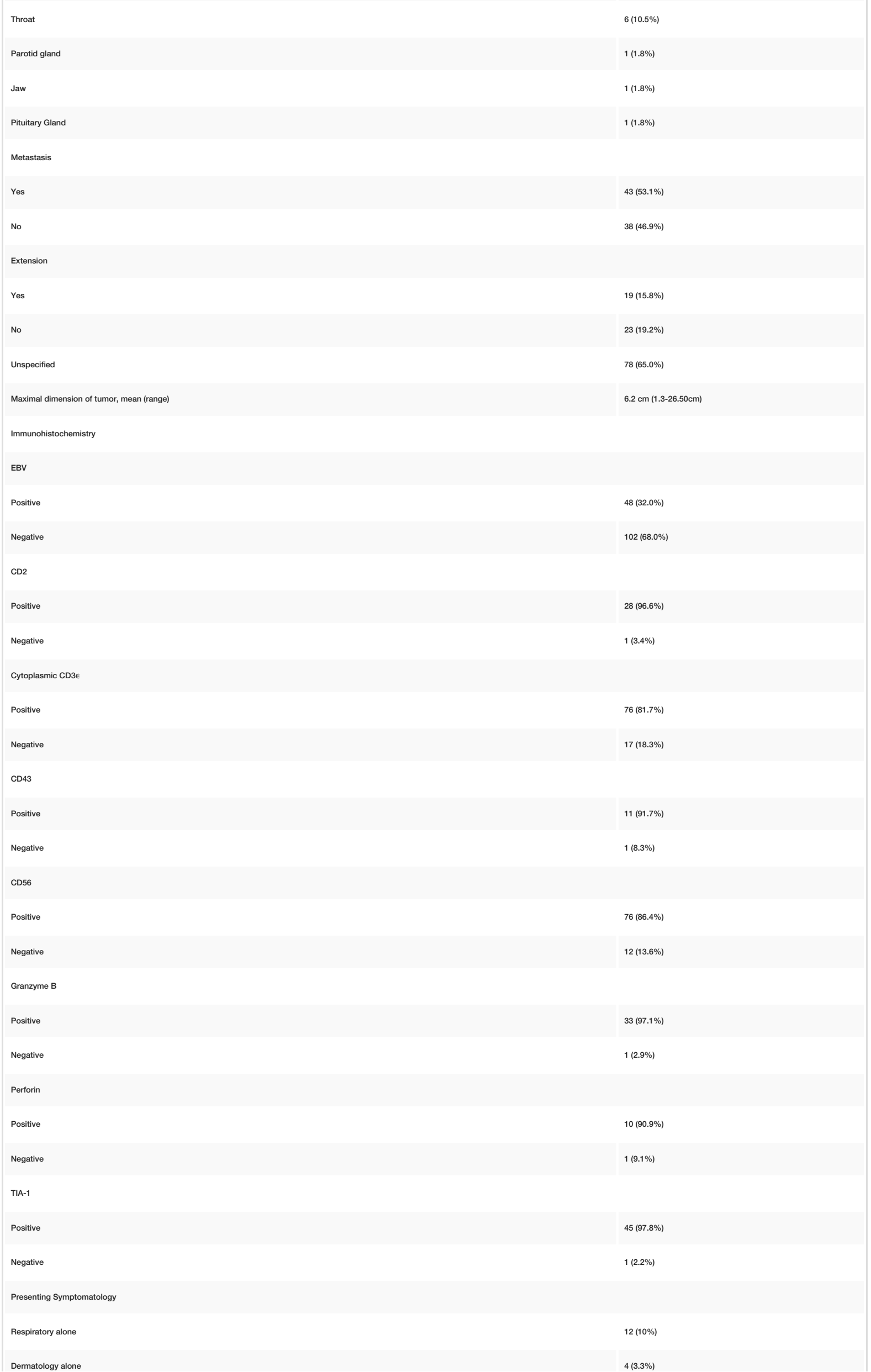




\section{Cureus}

Gl alone $\quad 2$ (1.7\%)

GU alone

Neurology alone

Systemic alone $\quad 4(3.3 \%)$

$\begin{array}{ll}\text { Swelling alone } & 7(5.8 \%) \\ & \end{array}$

$\begin{array}{ll}\text { Symptoms involving } 22 \text { major systems } & 38 \text { (31.7\%) }\end{array}$

$\begin{array}{lr}\text { Asymptomatic } & 4(3.3 \%) \\ & \end{array}$

\begin{tabular}{ll} 
Miscellaneous & $2(1.7 \%)$ \\
\hline &
\end{tabular}

\begin{tabular}{ll} 
Unspecified & $45(37.5 \%)$ \\
\hline
\end{tabular}

Imaging Modality

Computed Tomography (CT) alone $\quad 9(7.5 \%)$

$\begin{array}{ll}\text { Magnetic Resonance Imaging (MRI) alone } & 1(0.8 \%)\end{array}$

Positron Emission Tomography (PET) alone $\quad 2(1.7 \%)$

$\begin{array}{ll}\text { PET-CT alone } & 9(7.5 \%)\end{array}$

Endoscopy alone $22(1.7 \%)$

$\begin{array}{ll}\mathrm{MRI}+\mathrm{CT} & 5(4.2 \%)\end{array}$

$\begin{array}{lll}\text { PET-CT + CT } & 6(5.0 \%)\end{array}$

$\begin{array}{ll}\text { Radiography }+ \text { CT } & 1(0.8 \%)\end{array}$

Ultrasound + PET $1{ }^{10.8 \%)}$

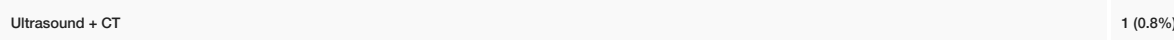

$>2$ imaging modalities $\quad 10(8.3 \%$

None 4 4(3.3\%)

other $1(0.8 \%)$

$\begin{array}{ll}\text { Unspecified } & 68 \text { (56.7\%) }\end{array}$

Initially Misciagnosed

Yes $30(25 \%$

No

Unspecified

Treatment Regimen

Chemotherapy alone $\quad 31$ (25.8\%)

$\begin{array}{ll}\text { Radiotherapy alone } & 6(5.0 \%)\end{array}$

Surgical Excision alone $\quad 1(0.8 \%$

$\begin{array}{ll}\text { Surgical Excision + Chemotherapy } & 2(1.7 \%)\end{array}$

$\begin{array}{ll}\text { Radiotherapy + Chemotherapy } & 15(12.5 \%)\end{array}$

\begin{tabular}{ll} 
SCT + Chemotherapy & $3(2.5 \%)$ \\
\hline &
\end{tabular}

Surgical Excision + Radiotherapy + Chemotherapy $\quad 5(4.2 \%)$

SCT + Radiotherapy + Chemotherapy $3(2.5 \%)$

SCT + Chemotherapy + Surgical Excision $1(0.8 \%)$

Supportive Treatment $221.7 \%$ 


\section{Cureus}

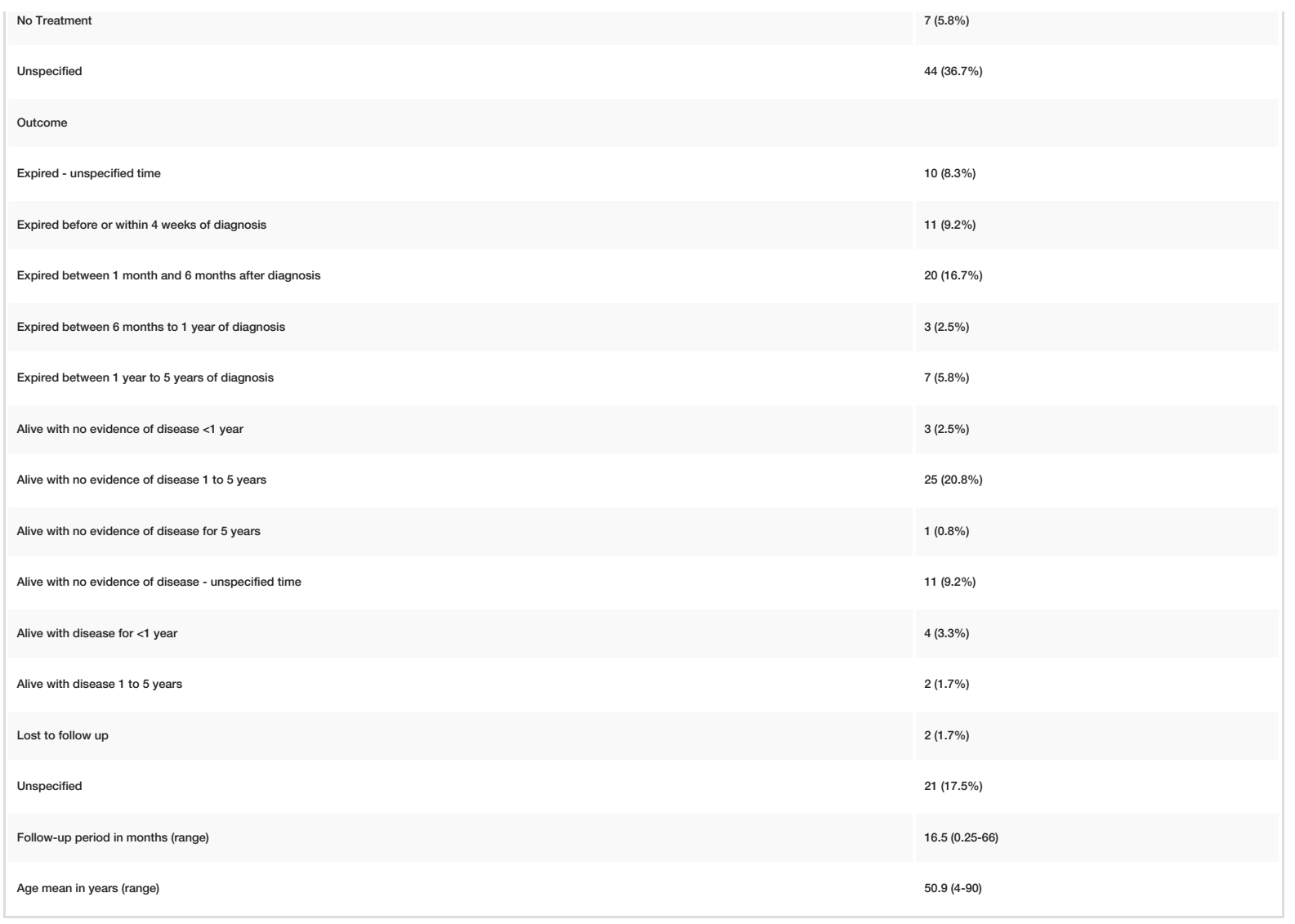

TABLE 1: Extranodal NK/T-cell lymphoma: demographics, pathogenic characteristics, and treatment regimens.

EBV: Epstein-Barr virus; GI: gastrointestinal; GU: genitourinary; CT: computed tomography; MRI: magnetic resonance imaging; PET: positron emission tomography; SCT: stem cell transplant.

The majority of cases were negative for EBV (68.0\%). In 53.1\% of cases, the tumor metastasized. Extension to nearby structures occurred in $15.8 \%$ of tumors. Positivity was present for CD2 in $96.6 \%$ of 29 cases, CD3€ in $81.7 \%$ of 93 cases, CD 43 in $91.7 \%$ of 12 cases, CD56 in $86.4 \%$ of 88 cases, Granzyme B in $97.1 \%$ of 34 cases, Perforin in $90.9 \%$ of 11 cases, and TIA-1 in $97.8 \%$ of 46 cases.

Stratified based on systemic origin, the most common symptoms were respiratory (10.0\%) although $31.7 \%$ of cases were associated with symptoms involving $\geqslant$ two organ systems. Mere swelling was present in $5.8 \%$ of cases while $3.3 \%$ of cases were asymptomatic. The most common primary site of the tumor was within the head and neck region (47.5\%). Within the head \& neck, the nose was the most common specific location (54.4\%) (Table 1).

The most common single imaging modality used to visualize ENKTL was evenly split between PET/CT and CT alone, both representing 7.5\% of cases. PET/CT and CT combined were used in 5.0\% of cases. More than two imaging modalities were utilized in ten cases (8.3\%), while no imagining was utilized in four cases (3.3\%) (Table 1).

Chemotherapy alone was the most commonly employed treatment modality (25.9\%). Radiotherapy alone was less common (5.0\%). Surgery was used alone in merely one case $(0.8 \%)$ and in conjunction with other treatment modalities in eight cases (6.7\%). Stem cell transplants were employed after ablation in seven cases (5.8\%) (Table 1).

Regarding the outcome, slightly less than half of the prognoses were poor, as $42.5 \%$ of patients expired at follow-up. Forty patients (33.3\%) were alive with no evidence of disease (ANED) while six patients (5.0\%) were alive with disease (AWD). The mean follow-up period was 16.5 months, ranging from a minimum of 0.25 to a maximum of 66 months (Table 1 ).

A series of non-parametric chi-square tests were conducted to elicit any associations between EBV positivity and certain variables pertaining to ENKTL including metastasis, subtype (nasal vs. non-nasal), 
immunocompromised status, age, and prognosis. In total, 153 cases of ENKTL were extracted from 66 articles. A p-value of 0.05 was used to determine statistical significance.

The first chi-square test is illustrated in Table 2. Out of the 153 cases of ENKTL investigated, 80 cases had information related to both EBV positivity and metastasis. The remaining 73 cases were missing at least one variable of interest. Therefore, 80 cases were included in this calculation. There was an association between EBV positivity and ENKTL metastasis $\left(\chi^{2}=4.36 ; C V=3.84 ; \mathrm{p}=0.037\right)$.

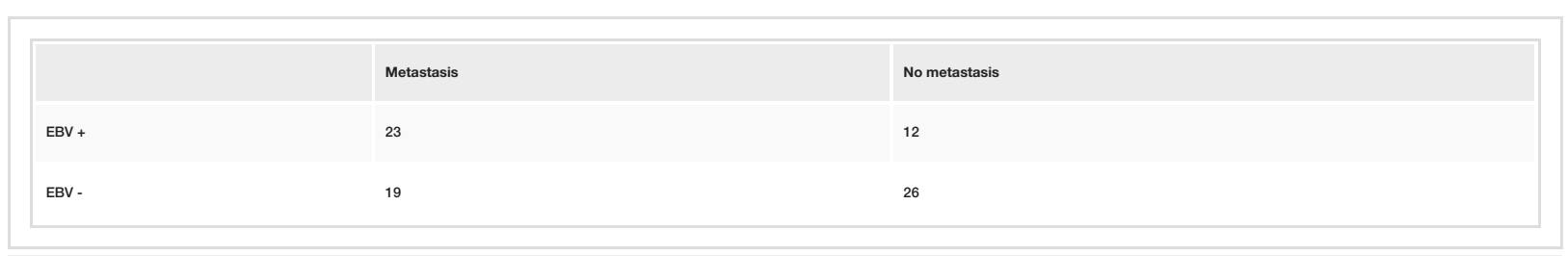

TABLE 2: EBV positivity stratified by whether primary cancer metastasized.

The Chi-square statistic is 4.36 . The $p$-value is 0.037 . The result is significant at $p<0.05$.

EBV: Epstein-Barr virus.

Out of the 153 cases of ENKTL investigated, 76 cases had information available for both EBV positivity and subtype. Therefore, 76 cases were included in this calculation. There was no association between EBV positivity and ENKTL subtype (nasal vs. non-nasal) $\left(\chi^{2}=0.05 ; \mathrm{CV}=3.84 ; \mathrm{p}=0.82\right)$.

Out of the 153 cases of ENKTL investigated, 25 cases had information available for both EBV positivity and immunocompromised status. We defined immunocompromised status as a patient having at least one of the following conditions: cancer, HIV/AIDS, chronic corticosteroid use, chemotherapy use, autoimmune disease, organ or bone marrow transplant. Therefore, 25 cases were included in this calculation. There was no association between EBV positivity and immunocompromised status $\left(\chi^{2}=0.04 ; \mathrm{CV}=3.84 ; \mathrm{p}=0.85\right)$.

Out of the 153 cases of ENKTL investigated, 115 cases had information available for both EBV positivity and age. Age was stratified into two categories: under 35 and 35 and older. Therefore, 115 cases were included in this calculation. There was no association between EBV positivity and age $\left(\chi^{2}=0.90 ; C V=3.84 ; p=0.34\right)$.

Out of the 153 cases of ENKTL investigated, 59 cases had information available for both EBV positivity and prognosis. Prognosis was stratified accordingly: alive with disease $<1$ year, alive with disease 1-5 years, alive with no evidence of disease (unspecified time), alive with no evidence of disease $<1$ year, alive with no evidence of disease 1-5 years, alive with no evidence of disease 5+ years, expired (unspecified time), expired before or within four weeks of diagnosis, expired between 1-6 months of diagnosis, expired between six months and one year of diagnosis, expired between one and five years of diagnosis, lost to follow up, and unspecified. Therefore, 59 cases were included in this calculation. There was no association between EBV positivity and prognosis $\left(\chi^{2}=17.2 ; C V=21.0 ; p=0.14\right)$.

\section{Discussion}

The primary purpose of this literature review is to identify the relationship between EBV and prognosis in ENKTL cases. The authors hypothesized that this study would reject the null hypothesis and reveal an association between EBV positivity and the prognosis of ENKTL. A secondary aim is to review current literature involving ENKTL and to discern if any relationships exist between EBV positivity and characteristics of this disease.

The results of this study reveal no association between EBV and ENKTL prognosis $\left(\chi^{2}=17.2 ; \mathrm{CV}=21.0 ; \mathrm{p}=\right.$ $0.14)$, however, EBV was associated with ENKTL metastasis $\left(\chi^{2}=4.36 ; \mathrm{CV}=3.84 ; \mathrm{p}=0.037\right)$.

The name NK/T-cell lymphoma was adopted to emphasize the expression of antigens associated with the most likely lineage for the malignant cells. Natural Killer cells are cytolytic cells in the primary immune response. Natural killer cells express variable T-cell lineage-associated antigens such as CD2 and CD7. Since the 1994 Pan Pacific Lymphoma Conference, the past 26 years have brought massive advancements in both understanding and treatment of this aggressive disorder that has a five-year survival rate of $25 \%$ to $50 \%$ [78]. Making a swift and accurate diagnosis of ENKTL and implementation of the standard of care treatment is crucial for enhancing the overall survival rate [4].

Extranodal NK/T-cell Lymphoma manifests in the sixth decade of life with a median age at presentation of 
52 years [79]. This review identified a similar median age of onset (50.9 years). The male predilection of prior studies was also consistent with the findings of this review (1.6:1 male to females) [79-82]. While the majority of the cases (54.6\%) affected Asian patients, Caucasian populations accounted for $9.2 \%$ of cases of ENKTL.

The majority of ENKTL cases present with respiratory symptoms including nasal obstruction, epistaxis, and/or a destructive mass involving the nose, sinuses, or palate $[80,81,83,84]$. B-symptoms including fever, night sweats, and weight loss are present in up to $35 \%$ of patients with ENKTL [79,82]. In this review, respiratory symptoms including cough, hemoptysis, sinusitis, dyspnea, stridor, nasal congestion, pharyngitis, rhinorrhea, and dysphonia were the presenting features in $10 \%$ of reported cases. The majority of cases (31.7\%) presented with symptoms pertaining to several body systems (Table 1).

The rarity and nonspecific presentation of ENKTL may delay diagnosis. In $25 \%$ of cases analyzed, the initial clinical diagnosis was erroneous, including dermatomyositis, uveitis, cellulitis, panniculitis, chronic sinusitis, pneumonia, and rhinocerebral mucormycosis.

Consistent with prior studies, the current literature review identified the head and neck region (47.5\%) as the most common location for ENKTL; more specifically, the nose was the most common location for disease (54.4\%). Extranodal NK/T-cell Lymphoma has metastatic potential that leads to disseminated disease and occurred in $53.1 \%$ of patients.

Definitive diagnosis of ENKTL is based on histopathology. Additionally, ENKTL demonstrates a unique immunohistochemical and genomic profile. ENKTL is characterized by a polymorphous lymphoid infiltrate that demonstrates an angioinvasive or angiodestructive pattern, invading vascular walls leading to fibrinoid and coagulative necrosis [85]. Although not quantified in this review, an angiodestructive growth pattern was visualized in the majority of cases included.

Over $90 \%$ of ENKTLs are of true NK cell origin [85]. Therefore, the most important criterion for the diagnosis of ENKTL is the demonstration of Natural Killer or T-cell markers [85]. The typical immunophenotype of ENKTL includes expression of $\mathrm{CD} 2$, cytoplasmic $\mathrm{CD} 3$ epsilon, $\mathrm{CD} 56$, and cytotoxic molecules such as granzyme B, TIA-1, and performing [86,87]. In the current review, 96.6\%, 81.7\%, and 86.4\% expressed CD2, cytoplasmic CD3 epsilon, and CD56 respectively; and in regard to cytotoxic molecules granzyme B, TIA-1 and perforin were expressed $97.1 \%, 90.9 \%$, and $97.8 \%$ of the time respectively (Table 1 ). A small number of cases of ENKTL demonstrate a clonal T-cell receptor (TCR) gene rearrangement, suggesting that tumor cells originate from cytotoxic T-cells [88].

EBV positivity as a prerequisite for diagnosis is still debated and remains controversial. Recent literature suggests that tumor location in the upper aerodigestive tract, presence of an angiocentric/angiodestructive growth pattern and necrosis, typical immunophenotype are sufficient for diagnosis of ENKTL, even if EBV infection is not identified via EBV DNA or Epstein-Barr encoding region in situ hybridization (EBER ISH) in tissue [89]. Epstein-Barr virus-negative ENKTL is a rare subtype with limited available research. In the previous series, EBV-negative ENKTL demonstrated similar clinicopathologic features compared to EBVpositive ENKTL, but EBV-negative cases occurred mainly in Chinese females, with a younger age of onset (32 years).

Prior to the revised classification system in 2016, earlier literature reviews found a significant difference in the EBV-positivity between the nasal type and non-nasal type of ENKTL [90]. However, this relationship was not replicated in this review $\left(\chi^{2}=0.05 ; C V=3.84 ; \mathrm{p}=0.82\right)$.

Since radiation therapy is an important component of treatment for ENKTL, proper radiologic delineation of target volumes is critical [91]. In 2011, MacDonald et al. determined that Positron Emission Tomography/Computed Tomography (PET/CT) was more useful in determining the stage and volume of ENKTL compared to Computed Tomography (CT), Magnetic Resonance Imaging (MRI), and PET alone [9193]. In this review, CT alone and PET/CT alone were tied for the most common (7.5\%) imaging modality used to localize ENKTL, and > two imaging modalities were used in $8.3 \%$ of the cases analyzed (Table 1 ). Pretreatment imaging should include imaging of the neck, chest, abdomen, and pelvis, nasal cavity, hard palate, anterior fossa, and nasopharynx [94]. Endoscopy and bone marrow examination are also important for therapy and prognosis [95].

Therapeutic options for ENKTL are rapidly expanding, and thus, a standardized protocol regarding treatment regimens is necessary [94]. For medically fit patients with localized disease, combination modality therapy (CMT) which includes simultaneous chemotherapy and radiation is recommended. CMT is associated with superior long-term survival and local disease control with acceptable levels of adverse effects compared to chemotherapy alone [94,96].

Staging distinguishes between localized versus advanced disease. Localized disease includes ENKTL confined to the upper aerodigestive tract with limited extension into adjacent structures or cases involving cervical lymph node involvement [94]. Advanced disease includes stage three or stage four nasal type ENKTL 
and all stages of extranasal ENKTL, other than stage one cutaneous extranasal ENKTL [94]. An intensive asparagine-based chemotherapy regimen is associated with superior outcomes with acceptable toxicity levels compared to other chemotherapy regimens [94]. Hematopoietic cell transplantation (HCT) is used for refractory cases of ENKTL or as a post-induction consolidation therapy [94].

The prognosis of ENKTL is vastly dependent on tumor location and staging [94] and localized disease has a better prognosis than advanced disease [10,97-99]. Based on retrospective evidence, the following features represent negative prognostic factors: age >60 years, stage three or stage four disease, distant lymph node involvement, EBV positivity, and extranasal type disease [100].

Prior evidence suggests that nasal ENKTL may demonstrate a better prognosis compared to extranasal ENKTL [79]. Levels of EBV DNA in the plasma or bone marrow correlate with patient outcomes. Pretreatment plasma EBV DNA levels >500 copies/mL was associated with lower estimated three-year progression-free survival (PFS; 52 versus 79\%) and overall survival (OS; 66 versus 97\%) compared to lower levels of EBV DNA [101].

The findings in this study are not without limitations. First, only two online databases were exhausted (PubMed and Google Scholar). Chi-square analysis that was carried out in this study does not allow us to establish a cause-and-effect relationship between study variables. Moreover, for the cases that were included in the literature review, full patient charts and medical histories were not attainable. This is important as we were unable to stratify for confounding variables and this data may not be representative of the target population.

\section{Conclusions}

The definition of ENKTL is controversial-especially when discussing EBV positivity. While some clinicians believe it is necessary for a definitive diagnosis of ENKTL, our research suggests that there is no association with patient prognosis. This project highlights the similarities between EBV positive and negative cases of ENKTL. The authors propose that the presence of an angiocentric/angiodestructive growth pattern and the typical immunophenotype with CD2, CD3€, CD43, CD56, Granzyme, Perforin, and TIA-1 markers is sufficient for a presumptive diagnosis of ENKTL. The investigators recommend that clinicians pay particularly close attention to those cases of ENKTL that are positive for EBV since they are associated with metastatic potential. We encourage clinicians to continue publishing cases of ENKTL so that the conclusions drawn from this study can be expanded upon.

\section{Additional Information}

\section{Disclosures}

Conflicts of interest: In compliance with the ICMJE uniform disclosure form, all authors declare the following: Payment/services info: All authors have declared that no financial support was received from any organization for the submitted work. Financial relationships: All authors have declared that they have no financial relationships at present or within the previous three years with any organizations that might have an interest in the submitted work. Other relationships: All authors have declared that there are no other relationships or activities that could appear to have influenced the submitted work.

\section{Acknowledgements}

We would like to thank Sabrina Fowler, Medical Student at Albert Einstein College of Medicine, for assisting with statistical computations, and Dani Stanbouly, Dental Student at Columbia University, for assisting in some preliminary statistical computations.

\section{References}

1. Tse E, Kwong YL: How I treat NK/T-cell lymphomas. Blood. 2013, 121:4997-5005. 10.1182/blood-2013-01453233

2. Jaffe ES, Chan JK, Su IJ, Frizzera G, Mori S, Feller AC, Ho FC: Report of the workshop on nasal and related extranodal angiocentric T/Natural Killer lymphomas: definitions, differential diagnosis and epidemiology. Am J Surg Pathol. 1996, 20:103-11. 10.1097/00000478-199601000-00012

3. Swerdlow SH, Campo E, Pileri SA, et al.: The 2016 revision of the World Health Organization classification of lymphoid neoplasms. Blood. 2016, 127:2375-90. 10.1182/blood-2016-01-643569

4. Tse E, Kwong YL: The diagnosis and management of NK/T-cell lymphomas. J Hematol Oncol. 2017, 10:85. 10.1186/s13045-017-0452-9

5. Allen PB, Lechowicz MJ: Management of NK/T-Cell lymphoma, nasal type. J Oncol Pract. 2019, 15:513-20. 10.1200/JOP.18.00719

6. Yang Y, Zhu Y, Cao JZ, et al.: Risk-adapted therapy for early-stage extranodal nasal-type NK/T-cell lymphoma: analysis from a multicenter study. Blood. 2015, 126:1424-1517. 10.1182/blood-2015-04-639336

7. Au WY, Weisenburger DD, Intragumtornchai $\mathrm{T}$, et al.: Clinical differences between nasal and extranasal natural killer/T-cell lymphoma: a study of 136 cases from the International Peripheral T-Cell Lymphoma Project. Blood. 2009, 113:3931-7. 10.1182/blood-2008-10-185256

8. Li S, Feng X, Li T, et al.: Extranodal NK/T-cell lymphoma, nasal type: a report of 73 cases at MD Anderson 
Cancer Center. Am J Surg Pathol. 2013, 37:14-23. 10.1097/PAS.0b013e31826731b5

9. Lan SK, Lin CW, Ho HC, Lee MS, Tzeng JE, Su YC: Penile metastasis secondary to nasal NK/T-cell lymphoma. Urology. 2008, 72:1014-5. 10.1016/j.urology.2008.05.029

10. Ferry JA, Sklar J, Zukerberg LR, Harris NL: Nasal lymphoma. A clinicopathologic study with immunophenotypic and genotypic analysis. Am J Surg Pathol. 1991, 15:268-79.

11. Lei KI, Chan LY, Chan WY, Johnson PJ, Lo YM: Diagnostic and prognostic implications of circulating cellfree Epstein-Barr virus DNA in natural killer/T-cell lymphoma. Clin Cancer Res. 2002, 8:29-34.

12. Chan JK, Yip TT, Tsang WY, et al.: Detection of Epstein-Barr viral RNA in malignant lymphomas of the upper aerodigestive tract. Am J Surg Pathol. 1994, 18:938-46. 10.1097/00000478-199409000-00009

13. Tse E, Leung R, Khong PL, Lau WH, Kwong YL: Non-nasal natural killer cell lymphoma: not non-nasal after all. Ann Hematol. 2009, 88:185-7. 10.1007/s00277-008-0562-0

14. Qi SN, Yang Y, Song YQ, et al.: First-line non-anthracycline-based chemotherapy for extranodal nasal-type NK/T-cell lymphoma: a retrospective analysis from the CLCG. Blood Adv. 2020, 4:3141-53. 10.1182/bloodadvances.2020001852

15. Yamaguchi M, Kwong YL, Kim WS, et al.: Phase II study of SMILE chemotherapy for newly diagnosed stage IV, relapsed, or refractory extranodal natural killer (NK)/T-cell lymphoma, nasal type: the NK-Cell Tumor Study Group study. J Clin Oncol. 2011, 29:4410-6. 10.1200/JCO.2011.35.6287

16. Kanate AS, DiGilio A, Ahn KW, et al.: Allogeneic haematopoietic cell transplantation for extranodal natural killer/T-cell lymphoma, nasal type: a CIBMTR analysis. Br J Haematol. 2018, 182:916-20. 10.1111/bjh.14879

17. Mo ZY, Wang P, Yang HW, Li WB, Liang QL: Esophageal metastasis secondary to extranodal nasal-type natural killer/T-cell lymphoma: A case report. Mol Clin Oncol. 2016, 5:207-9. 10.3892/mco.2016.861

18. Zhang F, Duan X, Liu K: A case report of an extranodal NK/T-cell lymphoma nasal type, occurring primarily in eyes with masquerade syndrome. Medicine. 2019, 98:e14836. 10.1097/MD.0000000000014836

19. Mori H, Ebisawa K, Nishimura M, Kanazawa K: Late diagnosis: a case of rapidly progressive extranodal NK/T cell lymphoma, nasal type. BMJ Case Rep. 2018, 2018:bcr2017221019. 10.1136/bcr-2017-221019

20. Ito H, Hiraiwa SI, Sugiyama T, et al.: An autopsy case of primary extranodal NK/T cell lymphoma (extranodal NK/T-cell lymphoma) of the bile duct. Clin J Gastroenterol. 2019, 12:209-12. 10.1007/s12328018-00931-1

21. Kawaguchi N, Izumi R, Kobayashi M, et al.: Extranodal NK/T-cell lymphoma mimicking granulomatous myositis. Intern Med. 2019, 58:277-82. 10.2169/internalmedicine.0859-18

22. Wong DJ, Parry LA, Bloch AE, Agar N: Extranodal NK/T cell lymphoma, nasal type, with retrobulbar extraconal phlegmon and naso-oral fistula. BMJ Case Rep. 2019, 12:e227160. 10.1136/bcr-2018-227160

23. Coha B, Vucinic I, Mahovne I, Vukovic-Arar Z: Extranodal lymphomas of head and neck with emphasis on NK/T-cell lymphoma, nasal type. J Craniomaxillofac Surg. 2014, 42:149-52. 10.1016/j.jcms.2013.04.004

24. Wan Ahmad Kammal WS, Mohd Rose I, Md Zin RR, Raja Ali RA, Masir N: Extranodal NK/T-cell lymphoma mimicking Crohn's colitis. Malays J Pathol. 2019, 41:195-9.

25. Zhang J, Wang M, Yang X, Liu C, He X: Primary pulmonary extranodal NK/T-cell lymphoma of nasal type misdiagnosed as pneumonia: a case report and literature review. Medicine. 2017, 96:e8914. 10.1097/MD.0000000000008914

26. Hallak B, Cairoli A, Bouayed S, Berthod G: Sinonasal relapses of a primary isolated extranodal NK/T-cell lymphoma of the testis. BMJ Case Rep. 2019, 12 :e230221. 10.1136/bcr-2019-230221

27. Ichikawa S, Fukuhara N, Shirai T, Ishii T, Ichinohasama R, Harigae H: Extranasal extranodal NK/T-cell lymphoma associated with systemic lupus erythematosus. Int J Hematol. 2020, 112:592-6. 10.1007/s12185020-02914-w

28. Kang DH, Huh J, Lee JH, Jeong YK, Cha HJ: Gastrosplenic fistula occurring in lymphoma patients: systematic review with a new case of extranodal NK/T-cell lymphoma. World J Gastroenterol. 2017, 23:6491-9. 10.3748/wjg.v23.i35.6491

29. Yang SJ, Ng CY, Yang CH, Lu PH: Doubly dangerous: extranodal NK/T-cell lymphoma. Am J Med. 2017, 130:669-72. 10.1016/j.amjmed.2017.02.003

30. Ichikawa S, Saito K, Fukuhara N, et al.: Primary adrenal extranodal NK/T-cell lymphoma: a case report and literature review. Leuk Res Rep. 2020, 14:100223. 10.1016/j.1rr.2020.100223

31. Liu JK, Sayama C, Chin SS, Couldwell WT: Extranodal NK/T-cell lymphoma presenting as a pituitary mass. Case report and review of the literature. J Neurosurg. 2007, 107:660-5. 10.3171/JNS-07/09/0660

32. Schimmel J, Renzi M, Fawaz B, Green J: A case of primary cutaneous extranodal NK/T-cell lymphoma in an African male. Int J Dermatol. 2019, 58:e172-3. 10.1111/ijd.14505

33. Du J, Ma PP, Wang QY, Chen CX, Li J: Extranodal NK/T-cell lymphoma, nasal type: a case report of 7-year natural course and review of literature. Int J Clin Exp Pathol. 2015, 8:9620-8.

34. Jabbari Azad F, Delavarian Z, Hatami M, Rahimi H, Abdolvahed MR: Extranodal NK/T cell lymphoma with destruction of the uvulae: A case report. Iran J Otorhinolaryngol. 2017, 29:101-8.

35. Kondo M, Mizutani M, Yamanaka K: Mosquito bite-induced localized NK/T-Cell lymphoma relapsed in a patient with complete remission of extranodal NK/T-cell lymphoma, nasal type. Case Rep Dermatol. 2019, 11:194-7. 10.1159/000501358

36. Tamoto Y, Ishida R, Shiogama K, et al.: Extranodal NK/T-cell Lymphoma, nasal type accompanied by PR3ANCA-associated glomerulonephritis. Intern Med. 2017, 56:2007-12. 10.2169/internalmedicine.56.8365

37. Mizuno H, Koya J, Fujioka Y, et al.: Extranodal NK/T cell lymphoma in a living donor liver transplant recipient. Ann Hematol. 2017, 96:1051-2. 10.1007/s00277-017-2969-y

38. Sitthinamsuwan P, Pongpruttipan T, Chularojmontri L, Pattanaprichakul P, Khuhapinant A, Sukpanichnant S: Extranodal NK/T cell lymphoma, nasal type, presenting with primary cutaneous lesion mimicking granulomatous panniculitis: a case report and review of literature. J Med Assoc Thai. 2010, 93:1001-7.

39. Rahal A, Reddy PS, Alvares C: Extranodal NK/T-Cell lymphoma, nasal type, presenting as a breast mass . Cureus. 2015, 7:e408. 10.7759/cureus.408

40. Tsao L, Draoua HY, Mansukhani M, Bhagat G, Alobeid B: EBV-associated, extranodal NK-cell lymphoma, nasal type of the breast, after heart transplantation. Modern Pathol. 2004, 17:125-30.

10.1038/sj.modpathol.3800040 
41. Fréling E, Granel-Brocard F, Serrier C, Ortonne N, Barbaud A, Schmutz JL: Extranodal NK/T-cell lymphoma, nasal-type, revealed by cutaneous breast involvement. Ann Dermatol Venereol. 2015, 142:104-11. 10.1016/j.annder.2014.11.007

42. Ge H, Wu X, Shen J, Chen J, Chen Y, Zhang Y: A case report of extranodal NK/T-cell lymphoma in patient with chronic lymphocytic leukemia. Medicine. 2018, 97:e11619. 10.1097/MD.0000000000011619

43. Kunami N, Takamatsu Y, Fujita M, et al.: Extranodal NK/T-cell lymphoma arising from soft tissue of the left forearm. Jpn J Clin Hematol. 2010, 51:422-6.

44. Cerroni L, Massone C, Kutzner H, Mentzel T, Umbert P, Kerl H: Intravascular large T-cell or NK-cell lymphoma: a rare variant of intravascular large cell lymphoma with frequent cytotoxic phenotype and association with Epstein-Barr virus infection. Am J Surg Pathol. 2008, 32:891-8. 10.1097/PAS.0b013e31815d29c9

45. Tsuyama N, Asaka R, Dobashi A, et al.: Epstein-Barr virus-negative extranodal "true" natural killer-cell lymphoma harbouring a KDM6A mutation. Hematol Oncol. 2018, 36:328-35. 10.1002/hon.2459

46. Chang BH, Stork L, Fan G: A unique case of adolescent CD56-negative extranodal NK/T-cell lymphoma, nasal type. Pediatr Dev Pathol. 2008, 11:50-4. 10.2350/06-07-0140.1

47. Shaw PH, Cohn SL, Morgan ER, Kovarik P, Haut PR, Kletzel M, Murphy SB: Natural killer cell lymphoma: report of two pediatric cases, therapeutic options, and review of the literature. Cancer. 2001, 91:642-6. 10.1002/1097-0142(20010215)91:4<642::aid-cncr1047>3.0.co;2-2

48. Kim HJ, Kim SH, Oh SH: CD56-negative extranodal NK/T-Cell Lymphoma, nasal type, with extranasal cutaneous involvement. Ann Dermatol. 2015, 27:618-20. 10.5021/ad.2015.27.5.618

49. Omori M, Oishi N, Nakazawa T, et al.: Extranodal NK/T-cell lymphoma, nasal type of the uterine cervix: a case report. Diagn Cytopathol. 2016, 44:430-3. 10.1002/dc.23439

50. Shimatani Y, Nakano Y, Tsuyama N, et al.: Extranodal NK/T-cell lymphoma, nasal type, manifesting as rapidly progressive dementia without any mass or enhancing brain lesion. Neuropathology. 2016, 36:456-63. 10.1111/neup. 12285

51. Terroso G, Aleixo J, Bernardes M, Mariz E, Fonseca E, Costa L: Nasal type extranodal NK/T cell lymphoma diagnosed in a patient with rheumatoid arthritis under methotrexate. Acta Reumatol Port. 2014, 39:77-81.

52. Fang JC, Zhou J, Li Z, Xia ZX: Primary extranodal NK/T cell lymphoma, nasal-type of uterus with adenomyosis: a case report. Diagn Pathol. 2014, 9:95. 10.1186/1746-1596-9-95

53. Alegría-Landa V, Manzarbeitia F, Salvatierra Calderón MG, Requena L, Rodríguez-Pinilla SM: Cutaneous intravascular natural killer/T cell lymphoma with peculiar immunophenotype. Histopathology. 2017, 71:994-1002. 10.1111/his.13332

54. Kato T, Tanabe J, Kanemoto M, Kobayashi C, Morita S, Karahashi T: A case of extranodal NK/T-cell lymphoma, nasal type mimicking typical manifestations of adult-onset Still's disease (AOSD) with hemophagocytic syndrome: diagnostic consideration. Modern Rheumatol. 2009, 19:675-80. 10.1007/s10165-009-0204-y

55. Maeng YI, Lee SJ: Metachronous extranodal natural killer/T-cell lymphoma of nasal type and primary testicular lymphoma. Yeungnam Univ J Med. 2021, 38:231-4. 10.12701/yujm.2020.00675

56. Selvamalar V, Thamby SP, Al-Hatamleh M, Mohamud R, Abdullah B: A diagnostic dilemma of sinonasal T cell lymphoma: report of a unique case and literature review. Gulf J Oncol. 2019, 1:83-9.

57. Marzouki-Zerouali A, Charbit L, Mitcov M, Violon F, Schmutz JL, Moawad S, Bursztejn AC: Extra-nodal NK/T-cell lymphoma, nasal-type, revealed by cutaneous and ocular involvement. Ann Dermatol Venereol. 2019, 146:626-33. 10.1016/j.annder.2019.01.027

58. Alhumidi A: Cutaneous Intravascular NK/T-cell lymphoma mimic panniculitis clinically, case report and literature brief review. Diagn Pathol. 2015, 10:107. 10.1186/s13000-015-0330-0

59. Tsukahara T, Takasawa A, Murata M, Okumura K, Nakayama M, Sato N, Hasegawa T: NK/T-cell lymphoma of bilateral adrenal glands in a patient with pyothorax. Diagn Pathol. 2012, 7:114. 10.1186/1746-1596-7-114

60. Jiang Q, Liu S, Peng J, et al.: An extraordinary T/NK lymphoma, nasal type, occurring primarily in the prostate gland with unusual CD30 positivity: case report and review of the literature. Diagn Pathol. 2013, 8:94. 10.1186/1746-1596-8-94

61. Quintanilla-Martinez L, Franklin JL, Guerrero I, et al.: Histological and immunophenotypic profile of nasal NK/T cell lymphomas from Peru: high prevalence of p53 overexpression. Human pathology. 1999, 30:84955. 10.1016/s0046-8177(99)90147-8

62. Ko YH, Ree HJ, Kim WS, Choi WH, Moon WS, Kim SW: Clinicopathologic and genotypic study of extranodal nasal-type natural killer/T-cell lymphoma and natural killer precursor lymphoma among Koreans. Cancer. 2000, 89:2106-16. 10.1002/1097-0142(20001115)89:10

63. Jung CK, Lee KY, Kim Y, Han K, Shim SI, Kim BK, Kang CS: Epstein-Barr virus infection, drug resistance and prognosis in Korean T- and NK-cell lymphomas. Pathol Int. 2001, 51:355-63. 10.1046/j.14401827.2001.01214.x

64. Ohshima K, Liu Q, Koga T, Suzumiya J, Kikuchi M: Classification of cell lineage and anatomical site, and prognosis of extranodal T-cell lymphoma -- natural killer cell, cytotoxic T lymphocyte, and non-NK/CTL types. Virchows Arch. 2002, 440:425-35. 10.1007/s00428-001-0545-1

65. Kim JE, Kim YA, Jeon YK, Park SS, Heo DS, Kim CW: Comparative analysis of NK/T-cell lymphoma and peripheral T-cell lymphoma in Korea: Clinicopathological correlations and analysis of EBV strain type and 30-bp deletion variant LMP1. Pathol Int. 2003, 53:735-43. 10.1046/j.1320-5463.2003.01552.x

66. Ko YH, Cho EY, Kim JE, et al.: NK and NK-like T-cell lymphoma in extranasal sites: a comparative clinicopathological study according to site and EBV status. Histopathology. 2004, 44:480-9. 10.1111/j.13652559.2004.01867.x

67. Ng SB, Lai KW, Murugaya S, et al.: Nasal-type extranodal natural killer/T-cell lymphomas: a clinicopathologic and genotypic study of 42 cases in Singapore. Mod Pathol. 2004, 17:1097-107. 10.1038/modpathol.3800157

68. Tai YC, Kim LH, Peh SC: High frequency of EBV association and 30-bp deletion in the LMP-1 gene in CD56 lymphomas of the upper aerodigestive tract. Pathol Int. 2004, 54:158-66. 10.1111/j.1440-1827.2003.01602.x

69. Cabrera ME, Eizuru Y, Itoh T, et al.: Nasal natural killer/T-cell lymphoma and its association with type 
"i"/XhoI loss strain Epstein-Barr virus in Chile. J Clin Pathol. 2007, 60:656-60. 10.1136/jcp.2005.034199

70. Matsuda M, Iwanaga T, Hashimoto S, Uesugi T, Itagaki N: Primary Epstein-Barr virus-negative nasal-type natural killer/T cell lymphoma of the testis. Leuk Res. 2009, 33:e119-20. 10.1016/j.leukres.2009.02.019

71. Teo WL, Tan SY: Loss of Epstein-Barr virus-encoded RNA expression in cutaneous dissemination of natural killer/T-cell lymphoma. J Clin Oncol. 2011, 29:e342-3. 10.1200/JCO.2010.31.4096

72. Bouchekioua A, Scourzic L, de Wever O, et al.: JAK3 deregulation by activating mutations confers invasive growth advantage in extranodal nasal-type natural killer cell lymphoma. Leukemia. 2014, 28:338-48. 10.1038/leu.2013.157

73. Kim HS, Lee HW, Kim WS, Ko YH: Systemic Epstein-Barr virus-negative mature natural killer-cell lymphoma with cutaneous and visceral involvement. APMIS. 2015, 123:990-2. 10.1111/apm.12458

74. Tian C, Wang Y, Zhu L, Yu Y, Zhang Y: Primary bone natural killer/T cell lymphoma, nasal type without EBV infection: a case report. Int J Clin Exp Pathol. 2015, 8:14836-9.

75. Nicolae A, Ganapathi KA, Pham TH, et al.: EBV-negative aggressive NK-cell leukemia/lymphoma: clinical, pathologic, and genetic features. Am J Surg Pathol. 2017, 41:67-74. 10.1097/PAS.0000000000000735

76. Asif S, Begemann M, Bennett J, Fatima R, Masood A, Raza S: Pembrolizumab in newly diagnosed EBVnegative extranodal natural killer/T-cell lymphoma: a case report. Mol Clin Oncol. 2019, 10:397-400. 10.3892/mco.2019.1805

77. Zeng LS, Huang WT, Qiu T, et al.: Correlation between the clinicopathological features and prognosis in patients with extranodal natural killer/T cell lymphoma. Chronic Dis Transl Med. 2017, 3:252-9. 10.1016/j.cdtm.2017.11.003

78. Kwong YL: Natural killer-cell malignancies: diagnosis and treatment. Leukemia. 2005, 19:2186-94. 10.1038/sj.leu.2403955

79. Au WY, Ma SY, Chim CS, et al.: Clinicopathologic features and treatment outcome of mature T-cell and natural killer-cell lymphomas diagnosed according to the World Health Organization classification scheme: a single center experience of 10 years. Ann Oncol. 2005, 16:206-14. 10.1093/annonc/mdi037

80. Li CC, Tien HF, Tang JL, et al.: Treatment outcome and pattern of failure in 77 patients with sinonasal natural killer/T-cell or T-cell lymphoma. Cancer. 2004, 100:366-75. 10.1002/cncr.11908

81. Chim CS, Ma SY, Au WY, et al.: Primary nasal natural killer cell lymphoma: long-term treatment outcome and relationship with the International Prognostic Index. Blood. 2004, 103:216-21. 10.1182/blood-2003-051401

82. Li YX, Liu QF, Fang H, et al.: Variable clinical presentations of nasal and Waldeyer ring natural killer/T-cell lymphoma. Clin Cancer Res. 2009, 15:2905-12. 10.1158/1078-0432.CCR-08-2914

83. Proulx GM, Caudra-Garcia I, Ferry J, et al.: Lymphoma of the nasal cavity and paranasal sinuses: treatment and outcome of early-stage disease. Am J Clin Oncol. 2003, 26:6-11. 10.1097/00000421-200302000-00002

84. Liu QF, Wang WH, Wang SL, et al.: Immunophenotypic and clinical differences between the nasal and extranasal subtypes of upper aerodigestive tract natural killer/T-cell lymphoma. Int J Radiat Oncol Biol Phys. 2014, 88:806-13. 10.1016/j.ijrobp.2013.12.005

85. Clinical manifestations, pathologic features, and diagnosis of extranodal NK/T cell lymphoma, nasal type . (2020). Accessed: February 20 2021: https://www.uptodate.com/contents/clinical-manifestationspathologic-features-and-diagnosis-of-extranodal-nk-t-cell-l....

86. Kanavaros P, Lescs MC, Brière J, et al.: Nasal T-cell lymphoma: a clinicopathologic entity associated with peculiar phenotype and with Epstein-Barr virus. Blood. 1993, 81:2688-95.

87. Elenitoba-Johnson KS, Zarate-Osorno A, Meneses A, Krenacs L, Kingma DW, Raffeld M, Jaffe ES: Cytotoxic granular protein expression, Epstein-Barr virus strain type, and latent membrane protein-1 oncogene deletions in nasal T-lymphocyte/natural killer cell lymphomas from Mexico. Mod Pathol. 1998, 11:754-61.

88. Lipford EH Jr, Margolick JB, Longo DL, Fauci AS, Jaffe ES: Angiocentric immunoproliferative lesions: a clinicopathologic spectrum of post-thymic T-cell proliferations. Blood. 1988, 72:1674-81.

89. Wang W, Nong L, Liang L, Zheng Y, Li D, Li X, Li T: Extranodal NK/T-cell lymphoma, nasal type without evidence of EBV infection. Oncol Lett. 2020, 20:2665-76. 10.3892/ol.2020.11842

90. Miyazato H, Nakatsuka S, Dong Z, et al.: NK-cell related neoplasms in Osaka, Japan. Am J Hematol. 2004, 76:230-5. 10.1002/ajh.20091

91. MacDonald SL, Mulroy L, Wilke DR, Burrell S: PET/CT aids the staging of and radiotherapy planning for early-stage extranodal natural killer/T-cell lymphoma, nasal type: a case series. Radiat Oncol. 2011, 6:182. 10.1186/1748-717X-6-182

92. Ji J, Liu XH, She NN, Li L, Zhang XB: Value of 18F-FDG PET/CT and PET in diagnosing and staging extranodal nasal type natural killer/T-cell lymphoma: a meta-analysis. J Clin Otorhinolaryngol Head Neck Surg. 2018, 32:1876-82. 10.13201/j.issn.1001-1781.2018.24.007

93. Guo R, Xu P, Cheng S, et al.: Comparison of Nasopharyngeal MR, 18 F-FDG PET/CT, and 18 F-FDG PET/MR for local detection of Natural Killer/T-Cell Lymphoma, nasal type. Front Oncol. 2020, 10:576409. 10.3389/fonc. 2020.576409

94. Treatment of extranodal NK/T cell lymphoma, nasal type . (2020). Accessed: February 20, 2021: https://www.uptodate.com/contents/treatment-of-extranodal-nk-t-cell-lymphoma-nasal-type.

95. Lunning MA: Extranodal NK/T-cell lymphoma, nasal type: shrouded no more. J Oncol Pract. 2019, 15:521-2. 10.1200/JOP.19.00523

96. Li YY, Feng LL, Niu SQ, et al.: Radiotherapy improves survival in early stage extranodal natural killer/T cell lymphoma patients receiving asparaginase-based chemotherapy. Oncotarget. 2017, 8:11480-8. 10.18632/oncotarget.14006

97. Cuadra-Garcia I, Proulx GM, Wu CL, Wang CC, Pilch BZ, Harris NL, Ferry JA: Sinonasal lymphoma: a clinicopathologic analysis of 58 cases from the Massachusetts General Hospital. Am J Surg Pathol. 1999, 23:1356-69. 10.1097/00000478-199911000-00006

98. Lee J, Park YH, Kim WS, et al.: Extranodal nasal type NK/T-cell lymphoma: elucidating clinical prognostic factors for risk-based stratification of therapy. Eur J Cancer. 2005, 41:1402-8. 10.1016/j.ejca.2005.03.010

99. Suzuki R, Suzumiya J, Yamaguchi M, et al.: Prognostic factors for mature natural killer (NK) cell neoplasms: aggressive NK cell leukemia and extranodal NK cell lymphoma, nasal type. Ann Oncol. 2010, 21:1032-40. 


\section{Cureus}

10.1093/annonc/mdp418

100. Kim SJ, Yoon DH, Jaccard A, et al.: A prognostic index for natural killer cell lymphoma after nonanthracycline-based treatment: a multicentre, retrospective analysis. Lancet Oncol. 2016, 17:389-400. 10.1016/S1470-2045

101. Wang ZY, Liu QF, Wang H, et al.: Clinical implications of plasma Epstein-Barr virus DNA in early-stage extranodal nasal-type NK/T-cell lymphoma patients receiving primary radiotherapy. Blood. 2012, 120:200310. 10.1182/blood-2012-06-435024 